\title{
A tomada de decisão baseada em atributos que influenciam a compra de máquinas agrícolas
}

\author{
Mario Fernando de Mello ${ }^{1}$ \\ José Fernando Schlosser ${ }^{2}$ \\ Henrique Zago Cervo ${ }^{3}$
}

\begin{abstract}
Resumo: Invariavelmente a compra de máquinas agrícolas é um processo complexo, uma vez que existem muitas variáveis envolvidas, além dos altos valores do investimento. As propriedades rurais, ou empresas rurais, ainda carecem de um melhor planejamento e uma melhor qualidade na tomada de decisão, uma vez que uma parcela considerável não utiliza ferramentas adequadas no processo decisório. Na medida que o empresário rural consegue estruturar informações na busca da melhor decisão, a assertividade da escolha reduz os riscos do investimento. Neste cenário é comum muitos empresários rurais tomarem decisões baseadas em suas vivências cotidianas, que também são importantes, e não baseadas em um processo estruturado que pode trazer maior segurança no investimento realizado. O presente estudo foi realizado em 52 empresas rurais localizadas no estado do Rio Grande do Sul. O objetivo principal do estudo foi identificar quais atributos são mais relevantes para o empresário rural na hora da decisão de compra de uma máquina agrícola. Como resultado do estudo, apresenta-se um ranqueamento de atributos considerados como mais influenciadores na hora da compra de uma máquina agrícola. Destaca-se que o atributo "qualidade do bem" foi considerado o mais importante pelas respostas dos empresários rurais.
\end{abstract}

Palavras-chave: Tomada de decisão; qualidade da decisão; atributos relevantes; decisão de compra.

The decision-making based on attributes that influence the purchase of agricultural machines

Abstract: Invariably buying agricultural machinery is a complex process, as there are many variables involved in addition to the high investment values. Farms, or farms, still need better planning and better decision-making since a considerable portion do not use adequate tools in the decision-making process. To the extent that the rural entrepreneur can structure information in search of the best decision, the assertiveness of the choice reduces the investment risks. In

\footnotetext{
${ }^{1}$ Doutor em Engenharia Agrícola pela Universidade Federal de Santa Maria, UFSM; Mestre em Engenharia de Produção pela Universidade Federal de Santa Maria, UFSM; Graduação em Engenharia Operacional Mecânica pela Universidade de Passo Fundo, UPF; Graduação em Ciências Contábeis pela Universidade Federal de Santa Maria, UFSM.

${ }^{2}$ Doutor em Energia Maquinaria y Riegos, Universidad Politécnica de Madrid, UPM, Madrid; Mestrado em Engenharia Agrícola pela Universidade Federal de Santa Maria, UFSM; Especialização em Direito Processual Civil pela Universidade para o Desenvolvimento do Estado e da Região do Pantanal, UNIDERP; Especialização em Mecanización Agraria Para Expertos de Parques de M. Centro di Studi Agricoli Borgo a Mozzano, CSABM, Itália; Graduação em Direito pela Universidade Luterana, ULBRA; Graduação em Agronomia pela Universidade Federal de Santa Maria, UFSM.

${ }^{3}$ Graduando em Administração pela Faculdade Antonio Meneghetti, AMF.
} 
Saber Humano, ISSN 2446-6298, V. 9, n. 15, p. 149-168, jul./dez. 2019.

this scenario it is common for many rural entrepreneurs to make decisions based on their daily experiences, which are also important, and not based on a structured process that can bring greater security in the investment made. The present study was conducted in 52 rural companies located in the state of Rio Grande do Sul. The main objective of the study was to identify which attributes are most relevant for the rural entrepreneur when deciding to buy an agricultural machine. As a result of the study, we present a ranking of attributes considered as most influential when buying a farm machine. It is noteworthy that the attribute "quality of good" was considered the most important by the responses of rural entrepreneurs.

Key-words: Decision making; quality of decision; relevant attributes; buying decision.

\section{Toma de decisiones basada en atributos que influyen en la compra de maquinaria agrícola}

Resumen: Comprar maquinaria agrícola es invariablemente un proceso complejo, ya que hay muchas variables involucradas además de los altos valores de inversión. Las granjas, o haciendas, todavía necesitan una mejor planificación y una mejor toma de decisiones, ya que una parte considerable no utiliza herramientas adecuadas en el proceso de toma de decisiones. En la medida en que el empresario rural pueda estructurar la información en la busca de la mejor decisión, la asertividad de la elección reduce los riesgos de inversión. En este escenario, es común que muchos empresarios rurales tomen decisiones basadas en sus experiencias diarias, que también son importantes, y no en un proceso estructurado que pueda brindar mayor seguridad en la inversión realizada. Este estudio se realizó en 52 empresas rurales ubicadas en el estado de Rio Grande do Sul. El objetivo principal del estudio era identificar qué atributos son más relevantes para el empresario rural al decidir comprar una máquina agrícola. Como resultado del estudio, presentamos una clasificación de atributos considerados como los más influyentes al comprar una máquina agrícola. Es de destacar que el atributo "calidad del bien" fue considerado el más importante por las respuestas de los empresarios rurales.

Palabras clave: toma de decisiones; calidad de decisión; atributos relevantes; Decisión de compra.

\section{Introdução}

O contexto atual de globalização na maioria das atividades produtivas deixa uma sensação de que os mercados agrícolas e de agronegócios mundiais se abrirão cada vez mais para os países produtores como o Brasil. Neste contexto, a pressão pelo aumento da produtividade e da lucratividade fazem com que as empresas rurais tenham que se adaptar o mais rápido possível, sob o risco de se inviabilizarem economicamente. Neste cenário globalizado, a agricultura moderna requer racionalização na utilização de recursos, fazendo com que as máquinas agrícolas ocupem papel fundamental e relevante em virtude de 
Saber Humano, ISSN 2446-6298, V. 9, n. 15, p. 149-168, jul./dez. 2019.

expressar alto valor, tanto técnico como econômico, elevando a importância da qualidade da decisão na hora de compra dessas máquinas.

Estudos sobre a administração das propriedades rurais apresentam lacunas em relação aos processos gerenciais e à tomada de decisão. Os desafios do atual agronegócio e essas lacunas teórico-práticas fazem com que o processo de tomada de decisão, muitas vezes, seja inadequado à gestão do negócio. Assim, infere-se que uma parcela considerável das propriedades rurais no Brasil não possui uma administração estruturada e, portanto, não se baseia na utilização de ferramentas de planejamento e de tomada de decisão.

Neste cenário, o processo de compra de uma nova máquina agrícola deve se pautar em atributos que auxiliem o produtor rural em sua decisão de compra. Dar ênfase à gestão e à qualidade da decisão é um desafio que deve ser enfrentado pelos produtores rurais em cada atividade a ser realizada.

Portanto, a crescente importância da agricultura no Brasil em função dos mercados globalizados impõe às empresas rurais uma constante redução de custos operacionais, aumento da produtividade e racionalidade nos investimentos em busca de uma melhor rentabilidade, o que requer maior assertividade na tomada de decisões. Nesse sentido, em função dos investimentos em máquinas e equipamentos serem em grande parte vultuosos, não há como negligenciar a escolha de atributos relevantes na hora da compra, uma vez que são muitos os apelos influenciadores na tomada de decisão. O processo de tomada de decisão é complexo e muitas variáveis se apresentam para serem consideradas.

Um processo estruturado com informações disponíveis ao decisor invariavelmente leva a uma decisão lógica coerente e menos passível de erros. Na literatura encontra-se alguns modelos de tomada de decisão e, entre eles, o modelo racional e o modelo comportamental. Enquanto o primeiro pressupõe informações perfeitas, o segundo preconiza que o decisor não tem um conjunto completo de alternativas e por isso busca a decisão por meio de experiências, hábitos e vivências. Tornar essas experiências em atributos racionais é um desafio e um caminho a ser perseguido pela empresa rural na busca da melhor decisão possível na hora de uma compra de máquina agrícola. Por isso, analisar as variáveis disponíveis e considera-las na tomada de decisão é um caminho para reduzir os riscos do negócio.

Assim, o objetivo principal deste estudo é identificar quais atributos são mais relevantes para os produtores rurais/empresários rurais, na hora de compra de uma 
Saber Humano, ISSN 2446-6298, V. 9, n. 15, p. 149-168, jul./dez. 2019.

máquina agrícola, promovendo um ranqueamento desses atributos com intuito de auxiliar os empresários na tomada de decisão.

\section{Referencial Teórico}

Neste capítulo serão abordados os principais temas relacionados ao presente estudo que irão embasar teoricamente a pesquisa.

\subsection{A importância do agronegócio no Brasil}

O agronegócio brasileiro é responsável por uma significativa fatia do Produto Interno Bruto (PIB). Segundo a Confederação Nacional da Agricultura-CNA (2017), representa cerca de $23,5 \%$ do PIB e é um dos responsáveis pelo saldo positivo da balança comercial brasileira. Ainda, segundo a CNA (2017), a população empregada no setor em 2015 foi de 19 milhões de trabalhadores, gerando uma participação nas exportações de UU\$ 96 bilhões no ano de 2017. Esses números grandiosos reforçam e acentuam a importância do agronegócio tanto para o país, como para os produtores rurais.

Analistas de mercado da empresa TSX Advisors (2017) destacam que para o Brasil superar as incertezas comuns de mercado é preciso protagonismo neste mercado. Vive-se um momento de transição no cenário econômico-social que envolve a matriz brasileira do agronegócio. Outra demanda que bate à porta brasileira é a demanda mundial por grãos. Considerando os dados da Programa das Nações Unidas para o Desenvolvimento (PNUD), nosso planeta terá um acréscimo de 2 bilhões de habitantes até 2050, sendo que Índia, China e alguns "tigres asiáticos" colocarão adicionalmente outro 1 bilhão de habitantes, consumindo commodities que antes não estavam no seu cardápio diário. Segundo os mesmos analistas, alguns volumes de alimento, a uma velocidade cada vez maior, deverão expandir o consumo/ano no mundo já nos próximos 10 anos:

$\bullet+450$ milhões de toneladas de grãos;

- +8 milhões de toneladas de carne bovina;

$\bullet+38,4$ milhões toneladas de leite.

O Brasil é parte do possível protagonismo desse cenário por três motivos básicos conjuntamente com EUA, Rússia, China e Índia. Tem população, área agricultável e PIB que podem ser articulados para atender tais demandas. 
Saber Humano, ISSN 2446-6298, V. 9, n. 15, p. 149-168, jul./dez. 2019.

A Tabela 1 demonstra a área cultivada no Brasil de 2013 a 2018. Os dados são do Levantamento Sistemático da Produção Agrícola do Instituto Brasileiro de Geografia Estatística-IBGE (2019).

\begin{tabular}{cccccc}
\hline SAFRA 2013 & SAFRA 2014 & SAFRA 2015 & SAFRA 2016 & SAFRA 2017 & SAFRA 2018 \\
\hline 71,5 & 78,1 & 75,8 & 78,6 & 75,1 & 78,8
\end{tabular}

Tabela 1 - Área cultivada no Brasil em milhões de hectares.

Fonte: IBGE $(2017 ; 2019)$.

De acordo com a Conab (2018), a receita bruta dos produtores rurais das lavouras de algodão, arroz, feijão, milho e soja da safra 2017/18, estimada com base nos dados do nono levantamento e nos preços recebidos pelos produtores em maio de 2018, atinge o total de R \$ 211,10 bilhões. Esse número é 25,1\% superior ao registrado na temporada anterior, quando a soma atingiu $\mathrm{R} \$ 168,80$ bilhões. O percentual de acréscimo supracitado pode ser explicado pela alta dos preços da soja, com crescimento na produção e principalmente nos preços praticados pela maior produção do algodão e sua valorização no mercado - demonstrado no Gráfico 1.

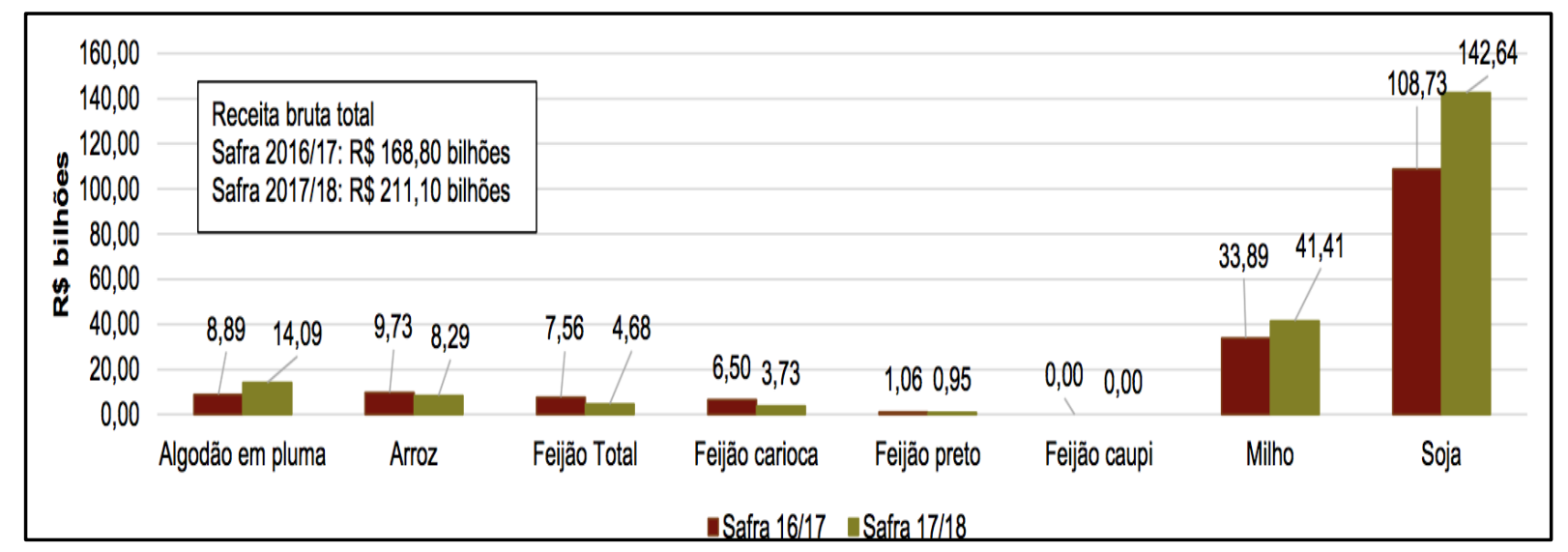

Gráfico 1 - Receita bruta dos produtores rurais - safras 2016/17 e 2017/18.

Fonte: Conab (2018).

Todo este contexto, com os indicadores apresentados, serve para reforçar a importância de toda cadeia do agronegócio, mas especialmente a importância das empresas rurais. Os investimentos das empresas rurais em máquinas agrícolas são relevantes e por isso a decisão de compra e/ou de substituição não deve ser tomada sem o uso de critérios adequados. Ressalta-se a importância de disponibilizar ao produtor rural subsídios 
Saber Humano, ISSN 2446-6298, V. 9, n. 15, p. 149-168, jul./dez. 2019.

concretos para qualificar sua tomada de decisão em novos investimentos (LEITNER; ALVES FILHO, 2019).

\subsection{Mecanização agrícola}

A revolução industrial e os passos tecnológicos subsequentes trouxeram a agricultura um estágio técnico e científico que possibilitou o aumento da produção sem a necessidade de ampliação da área de cultivo. Neste sentido, a mecanização agrícola é um importante componente básico na maioria das estratégias de desenvolvimento rural, aumento da produtividade e mão de obra qualificada (FRANCISCO, 2012). Ainda para o mesmo autor, o uso de máquinas e implementos para o preparo do solo é de fundamental importância para a agricultura, uma vez que aumenta a produtividade, reduz custos e aumenta a produção como um todo. Nas exigências da agricultura atual as máquinas e implementos possibilitam que o homem realize as tarefas necessárias com mais qualidade e produtividade nas mais diversas condições de trabalho.

Na visão de Schlosser (2003), a máquina está envolvida em quase todas etapas da produção e o custo da mecanização pode incidir em até $40 \%$ sobre o custo da produção, sendo, então, um item de muita importância na gestão da propriedade. Destaca ainda que a tomada de decisão é difícil, pois a situação econômica da agricultura não permite erros de grande dimensão sob risco de inviabilizar a continuidade do negócio.

A decisão de compra de uma máquina agrícola é uma tarefa complexa que exige a análise de muitas variáveis, desde especificações técnicas, complexidade da máquina até as condições do negócio, uma vez que os altos valores de investimentos na mecanização tornam as decisões a serem tomadas cada vez mais difíceis. A alocação de recursos produtivos, pelo proprietário rural, à atividade de uma propriedade agrícola, deve sempre minimizar custos. $\mathrm{O}$ investimento em máquinas e equipamentos, independentemente do tamanho da propriedade, deve ser realizado de forma racional, observando-se as características econômicas do empreendimento (FARIAS et al., 2011; JASPER; SILVA, 2013)

Quando se fala em mecanização de qualquer atividade não se pode deixar de mencionar a manutenção mecânica e todas as exigências ligadas a ela. Quais sejam:

- Treinamentos dos operadores e pessoal da manutenção;

- Peças de reposição; 
Saber Humano, ISSN 2446-6298, V. 9, n. 15, p. 149-168, jul./dez. 2019.

- Oficinas;

- Ferramentas.

Afinal, alertam os autores, toda mecanização requer a utilização de equipamentos mecânicos que certamente irão falhar, por isso a função manutenção não pode negligenciar e não observar os procedimentos operativos recomendados. Para cumprir os objetivos de disponibilidade e confiabilidade é necessário ampliar o conceito de apenas manter as condições básicas das máquinas e equipamentos. A manutenção precisa evoluir e, para cada um dos desafios - manter, melhorar e antecipar - existem métodos de trabalho e ferramentas específicas e cada etapa é uma evolução da anterior (PACCOLA, 2011; VELOSO, 2015).

Na visão de Oliveira e Nachiluk (2013), a intensificação do uso da mecanização agrícola nas propriedades rurais tem exigido novos investimentos em máquinas. À medida que o tamanho e a complexidade do sistema mecanizado aumentam, mais importante se torna o impacto da tomada de decisão por parte do empresário rural na hora da compra de uma máquina. A otimização do sistema mecanizado passa, necessariamente, por um adequado entendimento do empresário rural, das relações existentes entre os aspectos técnicos e econômicos da mecanização.

\subsection{Processo de tomada de decisão}

A atividade de tomar decisões é essencial para as organizações e/ou pessoas, pois acontece o tempo todo nos vários níveis e influencia o desempenho em negociações e em qualquer empreendimento. As decisões no mundo dos negócios geralmente refletem aspectos como preço, custo e lucro. Processo de tomada de decisão é o procedimento de identificar um problema ou uma oportunidade e selecionar uma linha de ação para resolvêlo. O decisor depara-se constantemente com decisões difíceis de serem tomadas, onde as consequências são importantes e os resultados, incertos (BEKMAN; COSTA NETO, 2009; SHIMIZU, 2010).

Segundo Schlosser (2003), o desafio para o produtor rural que queira progredir economicamente passa por:

a) Selecionar os equipamentos pela sua necessidade, com critérios técnicos e econômicos;

b) Encontrar equipamentos adequados para sua situação particular; 
Saber Humano, ISSN 2446-6298, V. 9, n. 15, p. 149-168, jul./dez. 2019.

c) Comprar um equipamento de custo compatível;

d) Investir em treinamento de operadores;

e) Qualificar a informação técnica.

Para Maximiano (2011), decisões são tomadas para resolver problemas ou aproveitar oportunidades, pois há um objetivo a ser atingido e deve-se superar obstáculos exigindo algum tipo de ação de reconhecimento da melhor alternativa. O mesmo autor destaca que a diferença entre a racionalidade e a intuição está na proporção de informação, de um lado, e opinião e sentimento de outro. Por isso, quanto maior a base de informações, mais racional é o processo, e vice-versa. Assim, o modelo racional pressupõe que os tomadores de decisão tenham informações sistematizadas para tomar a decisão e escolher entre as alternativas disponíveis.

Em trabalho realizado por Artuzo et al. (2015), nota-se que muitos produtores vêm adquirindo máquinas com excesso de potência e/ou implementos agrícolas além da necessidade, o que contribui para aumentar os custos de produção na propriedade rural. Destacam os autores que este fato vem ocorrendo devido à disponibilidade de financiamentos, período de carência e longo prazo para pagamento. Isso demonstra, e vem ao encontro do objetivo deste estudo, a necessidade de estudos de viabilidade, a adoção de melhores decisões através de ferramentas de planejamento e de seleção da melhor alternativa de negócio buscando a racionalidade na tomada de decisão por parte do produtor rural. Assim, o estabelecimento de um conjunto de informações pelo produtor rural é de crucial importância para a tomada de decisão em relação à compra de máquinas agrícolas.

A resolução de problemas e a tomada de decisão podem ser abordadas de várias maneiras diferentes e normalmente seguem a dois modelos: o modelo racional e o modelo comportamental. Tomar a decisão ótima que maximize os resultados é o que preconiza o modelo racional referente ao processo decisório. Dessa forma, o processo levaria a uma decisão ideal, independente de quem a tomasse. Na realidade, o modelo de tomada de decisão racional não tem a pretensão de descrever como as decisões são tomadas, mas, sim, como deveriam ser tomadas (CARAVANTES; PANNO; KLOECKNER, 2005; SOBRAL; PECI, 2008).

Já no modelo comportamental, o ambiente é marcado por incertezas e exige a necessidade de compreender quais são os elementos associados. O tomador de decisão não tem um conjunto completo de alternativas ou não as entende plenamente. Além disso, o 
Saber Humano, ISSN 2446-6298, V. 9, n. 15, p. 149-168, jul./dez. 2019.

sucesso na tomada de decisão depende de inúmeros fatores, tais como: responsabilidade perante a lei, conhecimentos teóricos e experiências, coordenação no processo de decisão, saber atuar em ambiente de risco (CARAVANTES; PANNO; KLOECKNER, 2005; GONTIJO; MAIA, 2004).

No Quadro 1 estão demonstradas as comparações entre o modelo racional e o modelo comportamental.

Modelo Racional

1. O tomador de decisão tem informações perfeitas, relevantes e acuradas.

2. O tomador de decisão tem uma lista de alternativas dentre as quais pode escolher.

3. O tomador de decisão é racional.

4. O tomador de decisão sempre tem em mente os melhores interesses da organização.

\section{Modelo Comportamental}

1. O tomador de decisão tem informações imperfeitas, incompletas e possivelmente imprecisas.

2. O tomador de decisão não tem um conjunto completo de alternativas ou não entende plenamente aquelas que têm à disposição.

3. O tomador de decisão tem uma racionalidade definida e se restringe a valores, experiências e hábitos.

4. O tomador de decisão escolherá a primeira alternativa minimamente aceitável.

Quadro 1 - Modelo racional x modelo comportamental de tomada de decisão.

Fonte: Adaptado de Caravantes, Panno e Kloeckner (2005).

No caso da comparação destes modelos e a ligação com o presente estudo, as características do modelo comportamental se aproximam mais dos produtores rurais onde muitas vezes eles devem tomar uma decisão considerando suas percepções e experiências, com informações e alternativas limitadas. O tomador de decisão é figura central e seu comportamento é que define as variações no processo decisório.

\section{Método}

As pesquisas científicas devem ser conduzidas e balizadas em premissas e pressupostos teóricos com a finalidade de fundamentar a interpretação do autor para garantir que seja considerada válida e então apresentar resultados coerentes. Muitas pesquisas trazem benefício ao pesquisador, porém não se deve esquecer que um dos principais objetivos das ciências é desenvolver o ser humano e, desta forma, este estudo deve contribuir com esta premissa (TRIVIÑOS, 2008; RICHARDSON, 2011).

O presente estudo está alicerçado em questionário elaborado aplicado junto a 52 empresas rurais localizadas na região central do Rio Grande do Sul. Segundo Malhotra (2012), um questionário tem três objetivos específicos: 
Saber Humano, ISSN 2446-6298, V. 9, n. 15, p. 149-168, jul./dez. 2019.

a) Deve transformar as informações desejadas em um conjunto de perguntas específicas que os entrevistados tenham condições de responder. Este objetivo, segundo o autor é sempre um grande desafio;

b) Precisa motivar e incentivar o entrevistado a deixar-se envolver pela entrevista, a cooperar e a completá-la. Um questionário bem elaborado motiva os entrevistados e aumenta os índices de resposta;

c) Deve sempre minimizar o erro de resposta.

Para que não houvesse dúvida por parte dos respondentes em relação à alguns atributos perguntados no questionário, apresenta-se a seguir as definições daqueles que poderiam incitar alguma dúvida.

a) Durabilidade: é a capacidade de um produto físico em preservar as suas características funcionais sem necessitar de manutenção ou reparações excessivas. A durabilidade é uma característica apreciada na maioria dos produtos, especialmente naqueles que têm um preço elevado. Se uma pessoa planear desembolsar bastante dinheiro para comprar um bem, em geral, espera-se que esse bem dure muitos anos;

b) Qualidade: qualidade significa também um atributo, propriedade, predicado ou condição particular de uma coisa ou pessoa que a diferencia das demais. A qualidade se refere ao grau de precisão, perfeição, ou é necessário que esteja conforme à determinado padrão. No que diz respeito aos produtos e/ou serviços vendidos no mercado, há várias definições para qualidade: "conformidade com as exigências dos clientes", "relação custo/benefício", "adequação ao uso", "valor agregado que produtos similares não possuem", "fazer certo à primeira vez", "produtos e/ou serviços com efetividade". Enfim, o termo é geralmente empregado para significar "excelência" de um produto ou serviço;

c) Facilidade de manutenção: facilidade de efetuar manutenção em certos componentes das máquinas sem precisar desmontar muita coisa. Ou seja, ter acesso fácil a determinados consertos na própria propriedade;

d) Disponibilidade de mão de obra para manutenção - Facilidade em encontrar mão de obra para manutenção com proximidade à propriedade e com curto espaço de tempo para atendimento;

e) Vida útil: este conceito é comumente usado na terminologia econômica. Deve-se ressaltar que a informação sobre a vida útil de um produto é determinante para a 
Saber Humano, ISSN 2446-6298, V. 9, n. 15, p. 149-168, jul./dez. 2019.

contabilidade de uma empresa. Por outro lado, saber quanto tempo vai servir uma máquina pode ajudar a programar sua amortização, contabilizar os possíveis reparos ou estabelecer uma estratégia de revenda. A vida útil de uma máquina está limitada a um determinado tempo, a partir do qual seu uso se torna antieconômico;

O contato com as empresas rurais foi realizado com a ajuda e indicação da EMATER Regional de Santa Maria e também com a indicação de outras empresas pelos próprios empresários rurais. No primeiro contato com a Gerência Regional da EMATER foi explanado o objetivo do estudo e a solicitação de indicação de empresas rurais que pudessem fazer parte da pesquisa. A partir da atuação colaborativa com a EMATER, os pesquisadores foram até as empresas rurais para a aplicação dos questionários. $\mathrm{O}$ questionário é composto de perguntas abertas e fechadas. Nas perguntas fechadas, foram relacionados 23 atributos que seriam relevantes para a tomada de decisão de compra de uma máquina agrícola, onde os produtores rurais escolheram notas de 1 a 5 para cada atributo, onde a nota 1 é sem importância e a nota 5 é muito importante. Nas perguntas abertas, foi solicitado aos produtores rurais que respondessem se usam algum critério para a decisão de compra e, em caso afirmativo, qual ou quais os critérios.

No contato com os empresários rurais foi explanado o objetivo do estudo e todos aceitaram participar, inclusive autorizando sua identificação.

Após a coleta, os dados foram tabulados com a utilização dos softwares Linguagem R e Microsoft Excel. Nesta etapa, demonstrada nos resultados, foi utilizada a estatística descritiva para a análise exploratória dos dados coletados.

\section{Discussões e Resultados}

Neste capítulo serão demonstrados os resultados relativos à pesquisa com as 52 empresas rurais.

A Tabela 2 demonstra a escolaridade dos empresários rurais pesquisados. Percebese uma predominância dos respondentes que possuem o ensino médio completo, com $55,77 \%$, sendo que apenas $23,08 \%$ possuem ensino superior completo. 
Saber Humano, ISSN 2446-6298, V. 9, n. 15, p. 149-168, jul./dez. 2019.

\begin{tabular}{lll}
\hline Escolaridade & Frequência & FR (\%) \\
\hline Ensino fundamental completo & 11 & 21,15 \\
Ensino médio completo & 29 & 55,77 \\
Ensino superior completo & 12 & 23,08 \\
\hline Total & $\mathbf{5 2}$ & $\mathbf{1 0 0 , 0 0}$ \\
\hline
\end{tabular}

Tabela 2 - Escolaridade dos empresários rurais.

Fonte: Autores (2019).

Na Tabela 3 está demonstrada a idade dos empresários pesquisados. Em relação à idade tem-se a idade média do produtor como sendo próxima a 44 anos. Porém, através do desvio padrão e dos números de máximo e mínimo, vê-se que os dados estão bem distribuídos, tendo produtores mais velhos e mais jovens que a média.

\begin{tabular}{cccccc}
\hline Variável & Mínimo & Máximo & Média & Mediana & Desvio-Padrão \\
\hline Idade & 19 & 73 & 44,31 & 48 & 13,93 \\
\hline
\end{tabular}

Tabela 3 - Idade dos empresários rurais.

Fonte: Autores (2019).

$\mathrm{Na}$ Tabela 4, por sua vez, foram tabulados os dados referentes à área utilizada pelas empresas rurais. Com a aleatoriedade na escolha dos pesquisados apareceram áreas muito pequenas e áreas grandes. Desta forma, uma análise pela média não é adequada. Neste caso, as técnicas estatísticas recomendam o uso da mediana, que é um instrumento mais eficaz para este tipo de distribuição de dados, já que localiza o valor central da distribuição.

\begin{tabular}{cccccc}
\hline Variável & Mínimo & Máximo & Média & Mediana & Desvio-Padrão \\
\hline Área total & 18 & 3222 & 480,23 & 190 & 711,72 \\
\hline
\end{tabular}

Tabela 4 - Área total em hectares.

Fonte: Autores (2019).

$\mathrm{Na}$ Tabela 5 está demonstrado o quanto cada cultura é plantada nas empresas rurais pesquisadas. Como cada empresário pode plantar mais de um tipo de cultura, as somas totalizam mais que 52 entrevistados e, assim, tem-se uma porcentagem relativa à totalidade dos empresários que plantam. Das 52 empresas rurais cerca de $81 \%$ plantam soja, $52 \%$ 
Saber Humano, ISSN 2446-6298, V. 9, n. 15, p. 149-168, jul./dez. 2019.

plantam arroz, apenas $8 \%$ plantam milho e também $27 \%$ que plantam outras culturas não discriminadas nas entrevistas.

\begin{tabular}{lll}
\hline Cultura cultivada & Frequência & FR $(\%)$ \\
\hline Soja & 42 & 80,77 \\
Arroz & 27 & 51,92 \\
Milho & 4 & 7,69 \\
Outros & 14 & 26,92 \\
\hline
\end{tabular}

Tabela 5 - Culturas cultivadas.

Fonte: Autores (2019).

Também foi perguntado aos empresários sobre o tipo de solo da propriedade. Para demonstrar estes dados foi utilizada uma tabela de dupla entrada, combinando os tipos de solo relatados, demonstrado na Tabela 6 .

\begin{tabular}{lcccccc}
\hline Tipo de solo & $\begin{array}{c}\text { De } \mathbf{0 \%} \text { a } \\
\mathbf{5 0 \%} \text { plana }\end{array}$ & FR $(\boldsymbol{\%})$ & $\begin{array}{c}\text { De } \mathbf{5 1 \%} \text { a } \\
\mathbf{7 5 \%} \text { plana }\end{array}$ & FR (\%) & $\begin{array}{c}\text { Mais de } \\
\mathbf{7 5 \%} \text { plana }\end{array}$ & FR (\%) \\
\hline Argiloso & 3 & 23,08 & 3 & 20,00 & 7 & 24,14 \\
Argiloso médio & 5 & 38,46 & 8 & 53,33 & 14 & 48,28 \\
Arenoso & 5 & 38,46 & 4 & 26,67 & 8 & 27,59 \\
\hline Total & $\mathbf{1 3}$ & $\mathbf{1 0 0 , 0 0}$ & $\mathbf{1 5}$ & $\mathbf{1 0 0 , 0 0}$ & $\mathbf{2 9}$ & $\mathbf{1 0 0 , 0 0}$ \\
\hline
\end{tabular}

Tabela 6 - Tipo de solo das propriedades.

Fonte: Autores (2019).

Esses dados pesquisados formam a caracterização das empresas pesquisadas, dando uma visão geral da importância da mecanização agrícola para a atividade. Desta forma, fica evidenciada a relevância do processo de decisão para a compra de máquinas agrícolas.

Na Tabela 7 pode-se verificar que 92\% dos empresários rurais segue algum tipo de critério na substituição das suas máquinas. Logo em seguida, na Tabela 8, estão demonstrados quais foram os critérios adotados. Ressalta-se que essa pergunta foi feita aos empresários sem direcionamento da resposta por parte do entrevistador, ou seja, foi uma pergunta aberta.

\begin{tabular}{lccc}
\hline & Resposta & Seguem critérios & FR $(\%)$ \\
\hline Sim & 48 & 92,31 \\
Não & 4 & 7,69
\end{tabular}


Saber Humano, ISSN 2446-6298, V. 9, n. 15, p. 149-168, jul./dez. 2019.

\begin{tabular}{lcc}
\hline Total & 52 & 100 \\
\hline Tabela $7-$ Empresários que dizem
\end{tabular}

Tabela 7 - Empresários que dizem seguir critérios para compra de máquinas.

Fonte: Autores (2019).

Esta questão, por ter sido do tipo aberta, teve muitas respostas diferentes. Mas, para analisa-la, foram agrupadas as respostas com mesma temática nas cinco categorias representadas na Tabela 8 . Nota-se que as respostas foram bem variadas e diferiram conforme o tipo de equipamento a ser comprado, mas se mantiveram em certa proporção. Os pontos importantes elencados pelos empresários entrevistados foram questões relacionadas às especificações técnicas e qualidade das máquinas, entre $25 \%$ e $30 \%$ respectivamente. Questões referentes a preços e oportunidade de compra ficaram logo atrás, com porcentagens em torno de $21 \%$ a $27 \%$, e questões ligadas à marca entre $20 \%$ e 24\%. A necessidade de compra e recomendação de outros empresários produtores também possui alguma relevância, entre $14 \%$ e $18 \%$ na hora da compra, e por último o custo com a manutenção, com porcentagens entre $7 \%$ e $9 \%$.

Comparando com trabalho de Martins et al. (2013), os resultados convergem no item de especificações/recomendações técnicas uma vez que naquele estudo $70,83 \%$ dos entrevistados atribuíram este critério como um dos mais importantes. Ainda naquele mesmo estudo, a recomendação de conhecidos ou parentes teve um percentual de 63,88\% de importância, diferentemente do presente estudo que apresentou entre $13 \%$ e $15 \%$ de importância neste quesito.

Catalán (2019) em seu estudo recomenda que o produtor, ao comprar uma máquina, deve ter uma lista de requisitos/especificações técnicas necessárias para a hora da decisão de compra. O autor criou uma matriz de decisão comparando especificações técnicas de quatro modelos de trator que podem auxiliar o decisor na hora da compra. Como de $25 \%$ a $30 \%$ dos empresários rurais aqui pesquisados dão também importância para este quesito, logo, existe convergência entre os estudos.

\begin{tabular}{lcccccc}
\hline Critérios para última compra de: & Trator & $\begin{array}{c}\text { F.R. } \\
(\boldsymbol{\%})\end{array}$ & Colhedora & $\begin{array}{c}\text { F.R. } \\
(\boldsymbol{\%})\end{array}$ & Pulverizador & $\begin{array}{c}\text { F.R. } \\
(\boldsymbol{\%})\end{array}$ \\
\hline $\begin{array}{l}\text { Referente a especificações técnicas e } \\
\text { qualidade }\end{array}$ & 23 & 25,27 & 23 & 30,26 & 26 & 30,23 \\
Referente a preço/oportunidade & 25 & 27,47 & 19 & 25,00 & 18 & 20,93 \\
Referente a marca & 22 & 24,18 & 15 & 19,74 & 19 & 22,09 \\
Referente a custos de manutenção & 8 & 8,79 & 5 & 6,58 & 8 & 9,30
\end{tabular}


Saber Humano, ISSN 2446-6298, V. 9, n. 15, p. 149-168, jul./dez. 2019.

Referente a recomendações de outros e necessidade de compra

$\begin{array}{lllll}13 & 14,29 & 14 & 18,42 & 15\end{array}$

17,44

\begin{tabular}{lllllll}
\hline Total & 91 & 100,00 & 76 & 100,00 & 86 & 100,00
\end{tabular}

Tabela 8 - Empresários rurais que seguem algum critério para a compra de máquinas.

Fonte: Autores (2019).

Na sequência, pela Tabela 9 são apresentados os 23 atributos relativos à pesquisa com os empresários rurais. Por tratar-se de pergunta fechada, foi informado aos respondentes que para cada um dos 23 atributos deveria ser dada uma nota de 1 a 5, com a seguinte categorização: nota 1 , sem importância; nota 2, pouco importante; nota 3, neutro; nota 4 , importante e nota 5 , muito importante.

Um dado relevante apontado pelos resultados, é que $26,92 \%$ dos respondentes acham que o vendedor de máquinas agrícolas não tem nenhuma importância no processo de compra por parte dos empresários. Já, no outro extremo, 73,08\% dos respondentes atribuíram nota máxima à qualidade do bem, como atributo mais relevante. 
Saber Humano, ISSN 2446-6298, V. 9, n. 15, p. 149-168, jul./dez. 2019.

\begin{tabular}{|c|c|c|c|c|c|c|c|c|c|c|}
\hline Atributo & $\begin{array}{c}\text { Sem } \\
\text { importância }\end{array}$ & $\begin{array}{c}\text { F.R. } \\
\%\end{array}$ & $\begin{array}{c}\text { Pouco } \\
\text { importante }\end{array}$ & $\begin{array}{c}\text { F.R. } \\
\%\end{array}$ & Neutro & $\begin{array}{c}\text { F.R. } \\
\%\end{array}$ & Importante & $\begin{array}{c}\text { F.R. } \\
\%\end{array}$ & $\begin{array}{c}\text { Muito } \\
\text { importante }\end{array}$ & $\begin{array}{c}\text { F.R. } \\
\%\end{array}$ \\
\hline Preço do bem & 0 & 0,00 & 1 & 1,92 & 11 & 21,15 & 18 & 34,62 & 22 & 42,31 \\
\hline Durabilidade do bem & 0 & 0,00 & 0 & 0,00 & 1 & 1,92 & 18 & 34,62 & 33 & 63,46 \\
\hline Qualidade do bem & 0 & 0,00 & 0 & 0,00 & 1 & 1,92 & 13 & 25,00 & 38 & 73,08 \\
\hline Tradição da marca & 3 & 5,77 & 3 & 5,77 & 11 & 21,15 & 23 & 44,23 & 12 & 23,08 \\
\hline $\begin{array}{l}\text { Facilidade de } \\
\text { manutencão } \\
\end{array}$ & 0 & 0,00 & 2 & 3,85 & 2 & 3,85 & 25 & 48,08 & 23 & 44,23 \\
\hline Custo da manutenção & 1 & 1,92 & 0 & 0,00 & 4 & 7,69 & 15 & 28,85 & 32 & 61,54 \\
\hline $\begin{array}{l}\text { Disponibilidade de mão } \\
\text { de obra para manutencão }\end{array}$ & 1 & 1,92 & 2 & 3,85 & 5 & 9,62 & 15 & 28,85 & 29 & 55,77 \\
\hline Vida útil do bem & 0 & 0,00 & 0 & 0,00 & 2 & 3,85 & 19 & 36,54 & 31 & 59,62 \\
\hline $\begin{array}{l}\text { Participação em feiras e } \\
\text { exposicões }\end{array}$ & 10 & 19,23 & 10 & 19,23 & 11 & 21,15 & 16 & 30,77 & 5 & 9,62 \\
\hline Estética e design & 11 & 21,15 & 11 & 21,15 & 13 & 25,00 & 15 & 28,85 & 2 & 3,85 \\
\hline Atendimento pós-venda & 1 & 1,92 & 2 & 3,85 & 3 & 5,77 & 14 & 26,92 & 32 & 61,54 \\
\hline Inovação do bem & 0 & 0,00 & 2 & 3,85 & 8 & 15,38 & 27 & 51,92 & 15 & 28,85 \\
\hline Intuição & 8 & 15,38 & 14 & 26,92 & 19 & 36,54 & 8 & 15,38 & 3 & 5,77 \\
\hline $\begin{array}{l}\text { Oportunidade de } \\
\text { negócio }\end{array}$ & 1 & 1,92 & 4 & 7,69 & 11 & 21,15 & 25 & 48,08 & 11 & 21,15 \\
\hline Influências dos técnicos & 7 & 13,46 & 9 & 17,31 & 10 & 19,23 & 17 & 32,69 & 9 & 17,31 \\
\hline $\begin{array}{l}\text { Influência de outros } \\
\text { produtores }\end{array}$ & 4 & 7,69 & 6 & 11,54 & 8 & 15,38 & 25 & 48,08 & 9 & 17,31 \\
\hline Valor da revenda & 1 & 1,92 & 3 & 5,77 & 3 & 5,77 & 29 & 55,77 & 16 & 30,77 \\
\hline Facilidade de revenda & 1 & 1,92 & 4 & 7,69 & 4 & 7,69 & 28 & 53,85 & 15 & 28,85 \\
\hline $\begin{array}{l}\text { Facilidade de } \\
\text { financiamento }\end{array}$ & 1 & 1,92 & 3 & 5,77 & 10 & 19,23 & 18 & 34,62 & 20 & 38,46 \\
\hline $\begin{array}{l}\text { Influência do vendedor } \\
\text { na tomada de decisão }\end{array}$ & 14 & 26,92 & 10 & 19,23 & 13 & 25,00 & 10 & 19,23 & 5 & 9,62 \\
\hline $\begin{array}{l}\text { Preço de venda da } \\
\text { cultura plantada } \\
\end{array}$ & 0 & 0,00 & 2 & 3,85 & 4 & 7,69 & 16 & 30,77 & 30 & 57,69 \\
\hline $\begin{array}{l}\text { Necessidade de aumento } \\
\text { da frota }\end{array}$ & 0 & 0,00 & 1 & 1,92 & 4 & 7,69 & 18 & 34,62 & 29 & 55,77 \\
\hline $\begin{array}{l}\text { Equipamento } \\
\text { demonstração }\end{array}$ & 0 & 0,00 & 3 & 5,77 & 19 & 36,54 & 17 & 32,69 & 13 & 25,00 \\
\hline
\end{tabular}

Tabela 9 - Frequência das respostas ao grau de importância dos atributos.

Fonte: Autores (2019).

De posse desses resultados procedeu-se o ranqueamento proposto no objetivo geral do estudo. A Tabela 10 apresenta os atributos em ordem decrescente de importância para os empresários rurais. Para confecção da tabela, somou-se a frequência das respostas dos empresários que responderam notas 4 ou 5 para os atributos e calculou-se as respectivas porcentagens. A partir disso, para o cálculo do peso dos atributos para os produtores 
Saber Humano, ISSN 2446-6298, V. 9, n. 15, p. 149-168, jul./dez. 2019.

atribuiu-se peso 100 para o atributo com maior porcentagem e foram calculados os pesos dos demais atributos em referência ao de peso 100 .

\begin{tabular}{|c|c|c|c|c|}
\hline Atributo & Classificação & Frequência & Porcentagem $(\%)$ & Peso \\
\hline Qualidade do bem & $1^{\mathrm{o}}$ & 51 & 98,07 & 100 \\
\hline Durabilidade do bem & $1^{\circ}$ & 51 & 98,07 & 100 \\
\hline Vida útil do bem & $2^{\circ}$ & 50 & 96,15 & 98 \\
\hline Facilidade de manutenção & $3^{\circ}$ & 48 & 92,30 & 94 \\
\hline Custo da manutenção & $4^{\circ}$ & 47 & 90,38 & 92 \\
\hline Necessidade de aumento da frota & $4^{\circ}$ & 47 & 90,38 & 92 \\
\hline Atendimento pós-venda & $5^{\circ}$ & 46 & 88,46 & 90 \\
\hline Preço de venda da cultura plantada & $5^{\circ}$ & 46 & 88,46 & 90 \\
\hline Valor da revenda & $6^{\circ}$ & 45 & 86,53 & 88 \\
\hline $\begin{array}{l}\text { Disponibilidade de mão de obra para } \\
\text { manutenção }\end{array}$ & $7^{\circ}$ & 44 & 84,61 & 86 \\
\hline Facilidade de revenda & $8^{\circ}$ & 43 & 82,69 & 84 \\
\hline Inovação do bem & $9^{\circ}$ & 42 & 80,76 & 82 \\
\hline Preço do bem & $10^{\circ}$ & 40 & 76,92 & 78 \\
\hline Facilidade de financiamento & $11^{\circ}$ & 38 & 73,07 & 75 \\
\hline Oportunidade de negócio & $12^{\circ}$ & 36 & 69,23 & 71 \\
\hline Tradição da marca & $13^{\circ}$ & 35 & 67,30 & 69 \\
\hline Influência de outros produtores & $14^{\circ}$ & 34 & 65,38 & 67 \\
\hline Equipamento de demonstração & $15^{\circ}$ & 30 & 57,69 & 59 \\
\hline Influências dos técnicos & $16^{\circ}$ & 26 & 50,00 & 51 \\
\hline Participação em feiras e exposições & $17^{\circ}$ & 21 & 40,38 & 41 \\
\hline Estética e design & $18^{\circ}$ & 17 & 32,69 & 33 \\
\hline Influência do vendedor na tomada de decisão & $19^{\circ}$ & 15 & 28,84 & 29 \\
\hline Intuição & $20^{\circ}$ & 11 & 21,15 & 22 \\
\hline
\end{tabular}

Tabela 10 - Ranqueamento dos atributos com notas 4 e 5 (importante e muito importante).

Fonte: Autores (2019).

Destacam-se na Tabela 10 os atributos "Qualidade do bem" e "Durabilidade do bem”, que foram classificados por 98,08\% dos empresários como importante ou muito importante. Dos 52 empresários pesquisados, 51 deram nota 4 ou 5 para estes atributos. Desta forma, estes dois atributos tiveram a maior frequência e, portanto, tiveram peso 100 , sendo referência para os pesos dos demais atributos. Assim, a Tabela 10 mostra o ranqueamento final dos 23 atributos pesquisados junto às 52 empresas rurais.

\section{Considerações Finais}


Saber Humano, ISSN 2446-6298, V. 9, n. 15, p. 149-168, jul./dez. 2019.

Ficou evidenciado, no presente estudo, que é importante o empresário rural seguir critérios na tomada de decisão para compra de máquinas agrícolas. As muitas variáveis que envolvem o processo de compra devem ser analisadas pelo decisor na busca da decisão mais assertiva. É recomendável que o empresário rural, para a tomada de decisão, busque uma combinação entre comportamento e técnica para que seu foco fique na busca do melhor investimento para sua empresa.

Estudos como este, aqui apresentado, servem como sistema de apoio às decisões, uma vez que a falta de informações pode acarretar um investimento que se tornará oneroso por muitos anos na empresa rural. Analisar os atributos mais relevantes, na visão de vários empresários, é uma maneira simples e prática de não tornar o momento da compra de uma nova máquina agrícola uma preocupação para o empresário.

O estudo demonstrou que dentre os 23 atributos pesquisados, no caso das perguntas fechadas e também quando a pergunta foi aberta, o atributo "qualidade do bem" foi o mais relevante na opinião dos 52 empresários rurais. Portanto, a complexidade e a necessidade de tomadas de decisões, muitas vezes urgentes, não deve afetar a busca de critérios, por parte do empresário rural, na busca da melhor escolha, uma vez que tanto o sub quanto o superdimensionamento do maquinário agrícola podem acarretar em aumento dos custos de produção.

Por fim, as características dos atributos relevantes, compiladas neste estudo, são capazes de auxiliar o empresário rural na busca da decisão mais assertiva na hora da compra de uma máquina agrícola.

\section{Referências}

ARTUZO, F. D.; JANDREY, W. F.; CASARIN, F.; MACHADO, J. A. D. Tomada de decisão a partir da análise econômica de viabilidade: estudo de caso no dimensionamento de máquinas agrícolas. Custos e @ gronegócio on line, v. 11, n. 3, jul./set. 2015.

BEKMAN, O. R.; COSTA NETO, P. L. O. Análise Estatística da Decisão. 2. ed. São Paulo: Blucher, 2009.

CARAVANTES, G.; PANNO, C.; KLOECKNER, M. Administração: teorias e processos. São Paulo: Pearson, 2005. 572 p.

CATALÁN, H. Cómo se compra un tractor? Revista Agrotécnica. Madrid, 2019. ISSN 1886-6514. CONFEDERAÇÃO NACIONAL DA AGRICULTURA - CNA. Exportações do Agro em 2017. Disponível em: <http://www.cnabrasil.org.br/estudos/exportacoes-do-agro-em-2017>. Acesso em: 18 jul. 2018. 
Saber Humano, ISSN 2446-6298, V. 9, n. 15, p. 149-168, jul./dez. 2019.

COMPANHIA NACIONAL DE ABASTECIMENTO - CONAB. Boletim CONAB julho 2018. Observatório Agrícola Acompanhamento da Safra Brasileira de Grãos. Disponível em: <https://www.conab.gov.br/info-agro/safras/graos>. Acesso em: 19 jul. 2018.

FARIAS, M. S.; SCHLOSSER, J. F.; FRANTZ, U. G.; NIETIEDT, G. H. Como escolher. Cultivar Máquinas, ano 10, n. 104, p. 36-37, 2011.

FRANCISCO, P. R. M.; CHAVES, I. de B.; LIMA, E. R. V. de. Mapeamento das terras para mecanização agrícola - Estado da Paraíba. Revista Brasileira de Geografia e Física, v. 5, n. 2, p. 233-249, 2012.

GONTIJO, A. C.; MAIA, C. S. C. Tomada de decisão, do modelo racional ao comportamento: uma síntese teórica. Caderno de Pesquisa em Administração, São Paulo, v. 11, n. 4, out/dez. 2004.

INSTITUTO BRASILEIRO DE GEOGRAFIA E ESTATÍSTICA - IBGE. Levantamento sistemático da produção agrícola 2017. Rio de Janeiro: IBGE, 2017. Disponível em: $\langle$ https://biblioteca.ibge.gov.br/visualizacao/periodicos/6/lspa_pesq_2017_dez.pdf >. Acesso em 18 jul. 2018.

INSTITUTO BRASILEIRO DE GEOGRAFIA E ESTATÍSTICA - IBGE. Cidades IBGE. Disponível em: <https://cidades.ibge.gov.br/brasil/rs/sao-gabriel/panorama>. Acesso em 18 jul. 2018.

JASPER, S. P.; SILVA, R. A. P. Estudo comparativo do custo operacional horário da mecanização agrícola utilizando duas metodologias para o Estado de São Paulo. Revista Nucleus, v. 10, n. 2, p. 119-126, 2013.

LEITNER, C. P. S.; ALVES FILHO, A. G. Estratégia de operações: uma abordagem teórica quanto à aplicabilidade do constructo para empreendimentos rurais produtores de grãos. Gestão \& Produção, v. 26, n. 1, p. e2400, 2019. Disponível em: <https://doi.org/10.1590/ 0104-530X2400-19>. Acesso em: maio 2019.

MAlHOTRA, N. K. Pesquisa de marketing: uma orientação aplicada. Tradução: Lene Belon Ribeiro, Monica Stefani; Revisão técnica: Janaina de Moura Engracia Giraldi. 6. ed. Porto Alegre: Bookman, 2012.

MARTINS, K. C.; GUSE, J. C.; DORR, A. C.; ROSSATO, M. V.; FREITAS, L. A. R. Gestão da Atividade Rural: um estudo junto aos compradores de máquinas agrícolas visitantes da Expointer Esteio/RS. Rev. Elet. em Gestão, Educação e Tecnologia Ambiental, v. 11, p. 2357-2365, 2013.

MAXIMIANO, A. C. A. Introdução à Administração. 8. ed. São Paulo: Atlas, 2011. 448p.

OLIVEIRA, M.D.M.; NACHILUK, K. Maior custo. Cultivar Máquinas, ano 13, n. 26, p. 10-12, 2013.

PACCOLA, J. E. Manutenção e operação de equipamentos móveis. São José dos Campos, SP: JAC, 2011. 272 p.

RICHARDSON, R. J. Pesquisa Social: Métodos e Técnicas. São Paulo: Atlas, 2011.

SCHLOSSER, J. F. Critérios de seleção. Cultivar Máquinas, ano 3, n. 16, p. 13-16, 2003.

SHIMIZU, T. Decisão nas organizações. 3. ed. São Paulo: Atlas, 2010. 
Saber Humano, ISSN 2446-6298, V. 9, n. 15, p. 149-168, jul./dez. 2019.

SOBRAL, F.; PECI, A. Administração: Teoria e pratica no contexto brasileiro. [S.1.]: Pearson Education, 2008.

TRIVIÑOS, A. N. S. Introdução à pesquisa em ciências sociais: a pesquisa qualitativa em educação. São Paulo: Atlas, 2008.

TSX ADVISORS. Protagonismo: Superando Incertezas no Agronegócio. 25 ago. 2017. Disponível em: $\quad<$ http://www.tsxadvisors.com.br/pt/blog/protagonismo-superando-incertezas-noagronegocio/>. Acesso em: 19 jul. 2018.

VELOSO, N. Gerenciamento e Manutenção de Equipamentos Móveis. 2. ed. São Paulo: Soberana, 2015. $284 \mathrm{p}$. 